\title{
Gender Differences in Observed and Perceived Stress and Coping in Couples with a Depressed Partner
}

\author{
Barbara Gabriel $^{1 *}$, Guy Bodenmann², Steven R. H. Beach ${ }^{3}$ \\ ${ }^{1}$ Psychological Sciences Research Institute, Université catholique de Louvain, Louvain la Neuve, Belgium \\ ${ }^{2}$ Psychological Institute, University of Zurich, Zurich, Switzerland \\ ${ }^{3}$ Center for Family Research, University of Georgia, Athens, GA, USA \\ Email: *m.gabrielba@gmail.com
}

Received 1 May 2016; accepted 20 May 2016; published 27 May 2016

Copyright (C) 2016 by authors and Scientific Research Publishing Inc.

This work is licensed under the Creative Commons Attribution International License (CC BY). http://creativecommons.org/licenses/by/4.0/

(c) (i) Open Access

\section{Abstract}

Recent results show higher perceived stress and more dysfunctional coping in depressed individuals, and suggest that dyadic approaches focused on enhancing couples coping can be useful in treating depression. At the same time, a long tradition of research on couples with a depressed partner suggests potential differences between couples who are more or less maritally distressed, as well as due to the gender of depressed spouse. The present study investigates the association of gender and marital satisfaction with stress and coping patterns in couples with a depressed partner by comparing 4 groups (maritally distressed and non-distressed couples in which either the male or female partner was suffering from depression). Both questionnaires and observed marital interaction tasks were used to assess all constructs. Evidence was found for greater stress and stress generating coping practices for depressed individuals and more dysfunctional dyadic coping in maritally distressed couples. In addition, we identified gender-related patterns associated with depression and marital distress that may be important in working with couples. Coping oriented couples approaches may benefit from consideration of gender differences to maximize therapeutic effectiveness with a range of couples with a depressed partner.

\section{Keywords}

Depression, Gender, Marital Relationship, Stress, Coping

\footnotetext{
${ }^{*}$ Corresponding author.
}

How to cite this paper: Gabriel, B., Bodenmann, G., \& Beach, S. R. H. (2016). Gender Differences in Observed and Perceived Stress and Coping in Couples with a Depressed Partner. Open Journal of Depression, 5, 7-20. 


\section{Introduction}

Depressed individuals experience greater stress but lower competency in dealing with stress (e.g. Felsten, 2002; Papageorgiou \& Wells, 2003). Indeed, considerable evidence suggests that depressed individuals generate some of the stress they experience (e.g. Hammen, 2006). Because depression may increase stress-generating responses, as depressive symptoms increase in response to external stressors, there is often an increase in future stress generated by the behavior of depressed individuals due to their use of dysfunctional coping strategies (e.g. Beach et al., 2014; Felsten, 2002; Moos, Shutte, Brennan \& Moos, 2005).

In addition to the important role of individual coping in depression, there is also a pivotal role for couple relationship variables and particularly dyadic influences on coping (Beach, Whisman \& Bodenmann, 2014; Bodenmann, Charvoz, Widmer \& Bradburry, 2004; Rehmann, Gollan, \& Mortimer, 2008). First, couple distress is an important stressor in its own right and has a negative impact on the intensity and course of depression (Whisman, 2001; Beach, Katz, Kim \& Brody, 2003), and depression has the potential to undermine couple relationships (Beach \& O’Learly, 1993; Davila, Karney, \& Bradbury, 2003), leading to a self-maintaining cycle (Beach, Whisman, \& Bodenmann, 2014). Second, dyadic coping (e.g. Bodenmann, 2000), defined as shared competencies in couples to cope together with daily stress, has been shown to be an important resource in managing both depressive symptoms and relationship well-being (Beach et al., 2014; Bodenmann, Pihet \& Kaiser 2006; Bodenmann et al., 2008). An intervention designed to enhance dyadic coping among couples with a depressed partner, Coping-Oriented Couples Therapy (COCT), demonstrated efficacy equivalent to Cognitive Therapy (CT) and Interpersonal Therapy (IPT) (e.g. Bodenmann et al., 2008). The initial success of COCT notwithstanding, its clinical utility could be enhanced by better explication of the variability in individual and couple coping patterns among couples who may vary in level of relationship distress as well as sex of the identified patient. Similarly, prior research on gender has identified differences that may be important in the maintenance and escalation of depression and marital distress (e.g. Gabriel, Beach \& Bodenmann, 2010; Bodenmann et al., 2004).

\subsection{The Current Study}

In the current investigation we examine patterns of stress and coping (individual and dyadic coping) in a sample of 62 depressed patients and their spouses, dividing them into four groups by crossing gender of the depressed patient with presence or absence of couple distress. This allows us to better characterize individual and dyadic patterns of coping characteristic of gender, patient vs. spouse, and level of marital distress. In a previously published study using the same sample and group design we investigated conflict behavior (Gabriel, Beach, \& Bodenmann, 2010). The current investigation includes both partners self-reports as well as observed interaction data from the dyad. The goal of the study was to identify patterns that might improve the potential utility of coping oriented couples approaches (e.g. COCT) in treating depression, as well as identify areas in which it may be important to adapt COCT or other marital approaches to gender typical needs.

\subsection{Depression, Stress Generation and Gender}

Depressed individuals experience a higher level of stress in multiple life domains (e.g. job, marital relationship, education of children) (Beach, Whisman \& Bodenmann, 2014; Johnson \& Jacob, 1997, 2000; Monroe \& Simons, 1991). However, on average, women are more affected by stress associated with children, family and life situation. Men on the other hand report more stress associated with work and other stress outside of the family (Almeida \& Kessler, 1998). Both men and women report substantial stress in response to problems with a romantic partner, suggesting that this is a common area for stress-generating processes to unfold. Underscoring the potential importance of attention to the different coping patterns of identified patients and their partners, several studies suggest that depression is associated with an exaggeration of gender typical and potentially stress-generating coping such that depressed individuals 1) display more emotional strategies (strategies of regulation of emotions) and less problem focused coping (practical and instrumental activities), 2) use dysfunctional cognitive strategies (e.g. rumination, wish-full thinking, self-blaming), and 3) show a higher passivity and avoidance in their coping behavior (e.g. Bodenmann et al., 2004; Felsten, 2002; Papageorgiou \& Wells, 2003; Rohde, Tilson, Lewinson \& Seeley, 1990). Suggesting the importance of attention to gender related patterns of coping, men are more likely to respond to stress with active, problem focused coping, but also more evasion and avoidance (McCall \& Struther, 1994). Women, on the other hand, tend to use more emotion focused as well as 
dysfunctional individual coping strategies (e.g. self-accusation, rumination, negative expression of emotion) and prefer to search for and to engage in social coping (Ptacek, Smith \& Dodge, 1994; Tamres, Janicki \& Helgeson, 2002; Vingerhoets \& van Heck, 1990). Outside the relationship, depression is significantly associated with higher rumination, problem-solving and emotional expression in depressed women and with higher avoidance in depressed men (e.g. Bodenmann et al., 2004). Depressed men also reported use of more effective and depressed women reported use of less effective individual coping strategies (Bodenmann et al., 2004).

\subsection{Depression, Dyadic Coping and Gender}

Tendencies to engage in dysfunctional coping behavior are potentially an important source of stress generation in couples with a depressed partner, and have attracted greater attention recently (Beach et al., 2014; Bodenmann et al., 2004, 2008). Meanwhile several studies using cross sectional as well as longitudinal designs have confirmed bidirectional associations between deficits in dyadic coping and depression (Bodenmann et al., 2004, 2008; Coyne, Thompson \& Palmer, 2002; Cranford, 2004). Depressed couples show more negative dyadic coping (hostile, ambivalent or superficial dyadic coping) and less positive dyadic coping (supportive dyadic coping) than couples without a depressed partner. Similarly, several studies have indicated more emotion focused and fewer problem focused behaviors among depressed persons as well as more passivity and avoidance and less positivity and higher negativity in dyadic coping (e.g. Bodenmann et al., 2004; Rohde, Tilson, Lewinsohn \& Seely, 1990). Other studies reported more negativity and ambivalence in support behaviors of partners of depressed persons (e.g. Benzano \& Coyne, 2000).

Research on gender related differences in dyadic stress regulation is currently divided. Some studies indicate less support provision overall and less effective support provision among men, and greater stress communication and support seeking among women (Bodenmann et al., 2006; Neff \& Karney, 2005; Tamres et al., 2002). In the context of depression significantly more stress communication and expression of negative emotions in depressed women along with more negative dyadic coping by partners of depressed women have been found (Bodenmann et al., 2004). However, others have found more similarities than differences between men's and women's support behavior (e.g. Ko \& Lewis, 2011; Verhofstadt, Buysse \& Ickes, 2007).

\subsection{Depression, Couple Distress, Dyadic Coping and Gender}

In addition to their role in depression, dyadic coping strategies are also important buffering and protective factors reducing the impact of external stress on marital problems and negativity in dyads (e.g. Bodenmann, Pihet \& Kaiser 2006; Bodenmann, Meuwly, Bradbury, Gmelch \& Ledermann, 2010; Falconier, Nussbeck \& Bodenmann, 2013). Maritally distressed couples show less positive and more negative behavior in stress and coping processes (Bodenmann et al., 2006; Pasch \& Bradbury, 1998). Women appear to be more affected by and engaged in marital stress as well as in stress and coping processes of their partners, whereas men show a greater tendency to withdraw from stress coming from the marital relationship or the partner (e.g. Bodenmann et al., 2006; Neff \& Karney, 2005). Prior research also suggests that during relationship conflicts women demonstrate more demanding behaviors whereas men are more likely to engage in withdrawal and avoidance, a gender typical pattern that is accentuated among maritally distressed couples (Christensen \& Heavey, 1990; Eldrige \& Christensen, 2002; Gottman, 1994). Only a few existing studies have investigated gender differences in marital interaction in couples with a depressed partner, finding higher negativity in couples with depressed wives and lower positivity in couples with depressed husbands, and these gender effects are more accentuated in the context of marital distress (Bodenmann et al., 2004; Gabriel et al., 2010; Johnson \& Jacob, 1997; 2000).

Given the prominence of stress and coping for both depressive symptomatology and marital problems, one might expect they could account for the association of marital problems and depression. However, the fact that not all couples with a depressed partner are maritally distressed (Beach, Smith, \& Fincham, 1994; Coyne et al., 2002; Rehman et al., 2008; Whisman, 2001) suggests that there are some important differences in the coping behavior of distressed versus non-distressed couples with a depressed partner.

\section{Method}

\subsection{Procedure}

Couples were recruited for participation in a treatment study focusing on depression from 2001 until 2006. 
Recruitment methods included newspaper advertisements and referrals from medical facilities in Switzerland. Criteria for participation in the study were a) meeting DSM criteria (DSM-IV: American Psychiatric Association, 1994) for unipolar depression using structured clinical interview SCID (German version: Wittchen et al., 1990), b) BDI > 11), c) an enduring romantic relationship (duration at least 1 year), d) sufficient cognitive abilities to complete self-report measures and e) agreement of the partner to participate on the study. Exclusion criteria included a) bipolar disorders, b) secondary depression with additional comorbidities (e.g. psychosis, personality disorders, alcoholism) as well as c) acute suicidal tendency. Patients not fitting inclusion criteria were referred to other therapy facilities. After a first screening on the phone, an appointment for a detailed diagnosis and videotaped marital interactions was set. Two or three weeks before the diagnostic interview, the questionnaires were mailed to the home address and were completed and returned before the scheduled session. The marital interactions were videotaped in a standardized setting at the couple's home after the diagnostic interview. Two ten minute interactions were recorded, each partner was asked to explore a relevant stress event that did not involve the spouse or dyadic conflict areas, while the other partner served as listener and support provider (see for more details below). The study received human subject's approval by the Swiss National Science Foundation (SNF) as well as from the governmental ethical committee.

\subsection{Participants}

62 couples (37 depressed wives, 25 depressed husbands) seeking therapy for depression, met the inclusion criteria and completed the questionnaires as well as the discussion task at pre-assessment. An average score of 54 points or more on the marital questionnaire (PFB: Hahlweg, 1996) was used to categorize couples on level of marital satisfaction (see Table 1). The groups contained 16 maritally distressed couples with a depressed wife (G1), 21 maritally non-distressed couples with a depressed wife (G2), 18 maritally distressed couples with a depressed husband (G3) as well as 7 maritally non-distressed couples with a depressed husband (G4). There were no significant differences between the four groups in age of husbands and wives, duration of the close relationships, years since first depression, or BDI scores of the depressed persons or their partners (see Table 1). However, there were significantly fewer children in G2 (maritally distressed with depressed husband) compared with G1 $(t(36)=2.81, p \leq 0.01)$ and G3 $(t(35)=3.58, p \leq 0.001)$. Chi-square comparisons revealed no significant group differences in the income $\left(\chi^{2}(3)=2.66, n s\right.$.) or in the education of wives $\left(\chi^{2}(3)=3.25, n s\right.$.) or husbands $\left(\chi^{2}(3)=5.91, n s\right.$.). Significantly more couples in G1 (maritally distressed with depressed wife) were married than couples of the other groups $\left(\chi^{2}(3)=11.25, p \leq 0.01\right)$. Husbands in G1 on the other hand showed a significant higher percentage of employment compared to husbands in the other groups $\left(\chi^{2}(3)=10.02, p \leq 0.05\right)$, whereas wives in G1 showed a significantly lower employment than wives in the two depressed husband groups $\left(\chi^{2}(3)=7.11, p \leq 0.1\right)$.

Table 1. Sample means and standard deviations for demographic variables by group.

\begin{tabular}{ccccccccccc}
\hline \multirow{2}{*}{ Variable } & \multicolumn{2}{c}{$\mathrm{G} 1(\mathrm{n}=16)$} & \multicolumn{2}{c}{$\mathrm{G} 2(\mathrm{n}=21)$} & \multicolumn{2}{c}{$\mathrm{G} 3(\mathrm{n}=18)$} & \multicolumn{2}{c}{$\mathrm{G} 4(\mathrm{n}=7)$} \\
\cline { 2 - 10 } & $M$ & $S D$ & $M$ & $S D$ & $M$ & $S D$ & $M$ & $S D$ & $F(3,58)$ \\
\hline Age wife (year) & 45.31 & 9.32 & 43.07 & 13.52 & 47.06 & 9.83 & 36.00 & 8.43 & 1.82 \\
Age husband (year) & 48.44 & 8.66 & 44.81 & 14.17 & 50.44 & 8.80 & 40.43 & 7.52 & 1.85 \\
Number of children & 1.91 & 1.13 & 0.95 & 0.93 & 2.00 & 0.85 & 1.07 & 1.54 & $4.42^{*}$ \\
Years in relationship & 18.98 & 9.95 & 14.94 & 12.75 & 20.13 & 10.9 & 10.32 & 6.93 & 1.76 \\
PFB spouse's & 41.80 & 9.80 & 69.14 & 9.79 & 42.90 & 10.42 & 64.05 & 7.92 & $35.07^{*}$ \\
BDI spouse's & 6.38 & 5.76 & 5.15 & 6.38 & 7.11 & 3.94 & 5.43 & 2.57 & 0.50 \\
PFB patient's & 39.36 & 13.48 & 67.61 & 11.39 & 41.79 & 10.30 & 65.43 & 11.31 & $26.46^{*}$ \\
BDI patient's & 25.89 & 7.46 & 24.55 & 7.29 & 26.50 & 8.22 & 21.36 & 6.81 & 0.87 \\
Years since first depression & 10.70 & 7.01 & 11.09 & 13.44 & 9.16 & 8.94 & 17.07 & 9.89 & 0.97 \\
PFB average & 40.58 & 10.61 & 68.37 & 9.47 & 42.34 & 7.83 & 64.74 & 8.50 & $40.68^{*}$ \\
\hline
\end{tabular}

${ }^{\mathrm{a}} \mathrm{G} 1$ = distressed couples with a depressed wife. G2 = nondistressed couples with a depressed wife. G3 = distressed couples with a depressed husband. $\mathrm{G} 4=$ nondistressed couples with a depressed husband. BDI = Beck Depression Inventory. PFB = Partnership Questionnaire. ${ }^{*} p \leq 0.05$. 


\subsection{Measures}

Stress and coping couple interaction task. Stress and coping sequences of 10 minutes for each partner were coded using categories of the coding system of the supportive emotional dyadic coping (SEDC: Bodenmann, 1997). To facilitate micro analytic coding of the duration and frequency of specific interaction codes, a computer supported system was utilized (Computer Aided Observation System CAOS: Bourquard, Bodenmann, \& Perrez, 1992-2005).

Two coders coded the interactions in five-minute time intervals independent from each other in a double-blind-administration. Interobserver reliabilities were characterized using the Kappa coefficient (Cohen, 1960). Kappas for verbal categories were greater than 0.75 in all cases, ranging from 0.75 to 1 , suggesting good reliability in the current study. The construct and predictive validity of the observing system have been demonstrated in prior research (Bodenmann, 2000).

Because of the infrequent occurrence of some behavior codes, behavior codes were aggregated into stress and support categories. Stress communication comprised two specific facets: a1) problem focused stress communication and a2) emotion focused stress communication. Support behavior was comprised of four specific facets: b1) problem focused dyadic coping (problem focused support and problem focused common dyadic coping), b2) verbal emotional supportive dyadic coping (verbal emotional support and emotional common dyadic), b3) nonverbal emotional supportive dyadic coping and b4) negative dyadic coping (ambivalent, artificial, verbal and nonverbal hostile dyadic coping) (see Bodenmann, 1997 for details). Relative frequencies (rf) were calculated by dividing the number of occurrences of a behavior category by the total duration of the interaction. For relative duration (rd), we used total duration of a behavior divided by the total duration of the interaction (e.g. Bakeman \& Gottman, 1997; Johnson \& Jacob, 1997).

Since homogeneity of variance represents one of the most important preconditions for analysis of variance (e.g. Bortz, 1993), we transformed the data to stabilize variance across groups. This is particularly important for categories with relatively few instances. We transformed the data by converting the raw data into a 6 point likert scale (0 to 5). Value ranges for the different points of the likert scale (1-5) were defined in terms of the median value of all values higher zero divided by five. Specifically, non-occurrence was assigned zero, a category was assigned " 1 " if it occurred but was less than $2 *$ (median/5), " 2 " if greater than " 1 " but less than 4 * (median/5), " 3 " if greater than " 2 " but less than $6 *$ (median/5), " 4 " if greater than " 3 " but less than 8 * (median/5) and " 5 " for all values greater than " 4 ". As a result of this transformation homogeneity of variance was markedly improved compared to the row data.

Partnership Questionnaire (Partnerschaftsfragebogen, PFB). The PFB (Hahlweg, 1996) has 30 items and uses a 4-point scale for each item. It measures marital quality and satisfaction and consists of three scales: quarrelling (e.g. "When we quarrel he or she keeps taunting me"), tenderness (e.g. "He or she caresses me tenderly") and closeness/communication (e.g. "We talk to each other for at least half an hour every day"). A total score below 54 points designates a low level of satisfaction and discriminates reliably between distressed and nondistressed couples (Hahlweg, 1996). The PFB is a widely used self-report scale with good internal consistency ( $\alpha^{1}$ $=0.94$ ) and has been examined with regard to validity (Hahlweg, 1996).

Beck Depression Inventory (BDI). The German version (Hautzinger, Bailer, Worall \& Keller, 1996) of the BDI questionnaire (Beck \& Steer, 1987) with 21 items $(\alpha=0.92)$ is a self-report measure of the intensity (4-point scale) of affective, cognitive, and somatic aspects of depression (e.g. "sadness", "pessimism, "past failure", "loss of pleasure"). The reliability and validity are well-established and the gender bias is low (e.g. Hautzinger et al., 1996).

Dyadic Coping Inventory (DCI). The DCI (Bodenmann, 2008) with 41 items $(\alpha=0.92)$ is a self-report measure of the frequency (6-point scale) of dyadic coping that includes perceptions of own and partner stress communication and dyadic support (positive, negative and common dyadic coping). Because we assessed both partners, we used only the 16 items of own dyadic coping including one's own emotional ("I show my partner through my behaviour when I am not doing well or when I have problems") and problem-focused stress communication ("I let my partner know that I appreciate his/her practical support, advice, or help") as well as one's own supportive and common emotional (e.g. "I show empathy and understanding", "We help one another to put the problem in perspective and see it in a new light"), one's own supportive and common problem-focused ("I take on things that my partner would normally do in order to help him/her out", "We try to cope with the problem together and search for ascertained solutions") and one’s own negative dyadic coping (e.g., "I blame my 
partner for not coping well enough with stress”) (Cronbach’s Alpha between $\alpha=0.71$ and 0.92). The criterion validity and construct validity of the DCI has been demonstrated in prior research (Bodenmann, 2008).

Individual Coping Questionnaire (Incope). The Incope (Bodenmann, 2000) is a questionnaire (5-point scale) with 23 items $(\alpha=0.80)$ developed on the basis of the COPE (Carver, Scheier, \& Weintraub, 1989) measuring the following subscales such as active problem-solving ("I attempt to tackle and solve the problem"), positive self-verbalization ("I persuade myself that I will make it"), rumination ("I ruminate for a long time and keep on thinking about the occurrence"), passivity/evasion ("I wait until things change on their own, even if I might be able to do something"), negative emotional expression ("I express my feelings without considering what this means for others"), substance use ("I consume something that calms me down (cigarettes, alcohol, sweets, tranquiliser") ( $\alpha=0.52$ to $\alpha=0.80$ ). Because of the low reliability of the subscale assessing substance use ( $\alpha$ $=.33$ ), this scale was not examined separately. This measure has yielded adequate concurrent and predictive validity in previous studies (Bodenmann, 2000).

The Stress Level Questionnaire (ASN). The ASN (Bodenmann, 2000) contains 15 items $(\alpha=0.77)$ (5-point scale) that cover several domains of possible daily hassles (i.e., household, marriage, well-being, outside the family), in an adapted version of the daily hassle scale by Kanner, Coyne, Schaefer \& Lazarus (1981). The subscales show good internal consistency ( $\alpha=0.55$ to 0.77 ). Reliability and validity are confirmed (Bodenmann, 2000).

\section{Results}

To investigate gender and group differences a two-way mixed MANOVA/ANOVA design with group as between and gender as within couple (wife/husband) factors was used. Additionally, because the depressed person could be either the husband or the wife, we also analyzed the data using index person (i.e. patient vs. partner) rather than gender as the within subject variable, and conducted a second set of two-way mixed MANOVA/ ANOVA analyses with group as between and index person as within (i.e., patient/partner) (see also Christensen \& Shenk, 1991; Kenny, Kashy, \& Cook, 2006). This strategy allowed us to characterize effects for both patient vs. spouse as well as for gender in relation to marital distress. Following the initial ANVOAs and MANOVAs post hoc analyses were used to identify specific cells of the design that differed (Bonferroni corrected t). For observed behavior codes of dyadic coping we conducted analysis of variance of relative duration (rd) and relative frequency (rf). Power analyses (Cohen, 1988) showed good power $(1-\beta=0.87)$ for within couples and interactions effects but limited power $(1-\beta=0.5)$ for between group effects to detect medium effect sizes with a sample of 62 couples.

\subsection{Depression, Stress Generation and Gender}

Hypotheses: Based on the presented literature, we expected more stress and more dysfunctional individual coping in depressed persons compared to their partners. Further we expected gender differences in the domains of perceived stress and in the individual coping strategies depending on gender.

Results: In the ANOVA for subscales of stress in different life domains (see Table 2), there was a significant multivariate effect (Hotteling's Trace) of patient vs. spouse $(F(1,58)=12.43, p \leq 0.001)$. In addition ANOVAs with subscales showed higher reported stress among depressed persons for their marriage $(F(1,58)=5.05, p \leq$ $0.05)$, household $(F(1,58)=31.43, p \leq 0.001)$, wellbeing $(F(1,58)=38.70, p \leq 0.001)$ and outside world $(F(1$, $58)=20.97, p \leq 0.001)$. Effects were present in each of the four groups for depressed patients compared to their partners (see Table 2).

Also for gender, there was a significant difference, although not so large as the effect for depression, with a multivariate effect (Hotteling's Trace) for stress across life domains $(F(1,58)=2.60, p \leq 0.05)$. Follow-up ANOVAs with subscales revealed that women reported significant higher stress in their marriage $(F(1,58)=$ $5.32, p \leq 0.05)$ and less well-being $(F(1,58)=5.2, p \leq 0.05)$ compared to men

With regard to subscales of self-reported coping there were significant multivariate effects (Hotteling's Trace) for depression $(F(1,58)=16.21, p \leq 0.001)$. In follow-up ANOVA analyses significant depression effects were found for all individual coping strategies (see Table 3, Figure 1). Depressed individuals reported more rumination $(F(1,58)=71.06, p<0.001)$, evasion $(F(1,58)=14.53, p<0.001)$ and negative emotion expression $(F(1$, $58)=9.88, p<0.01)$ than partners. Partners on the other hand reported more positive verbalization $(F(3,58)=$ $30.47, p<0.001)$ and active problem solving $(F(3,58)=23.88, p<0.001)$. 


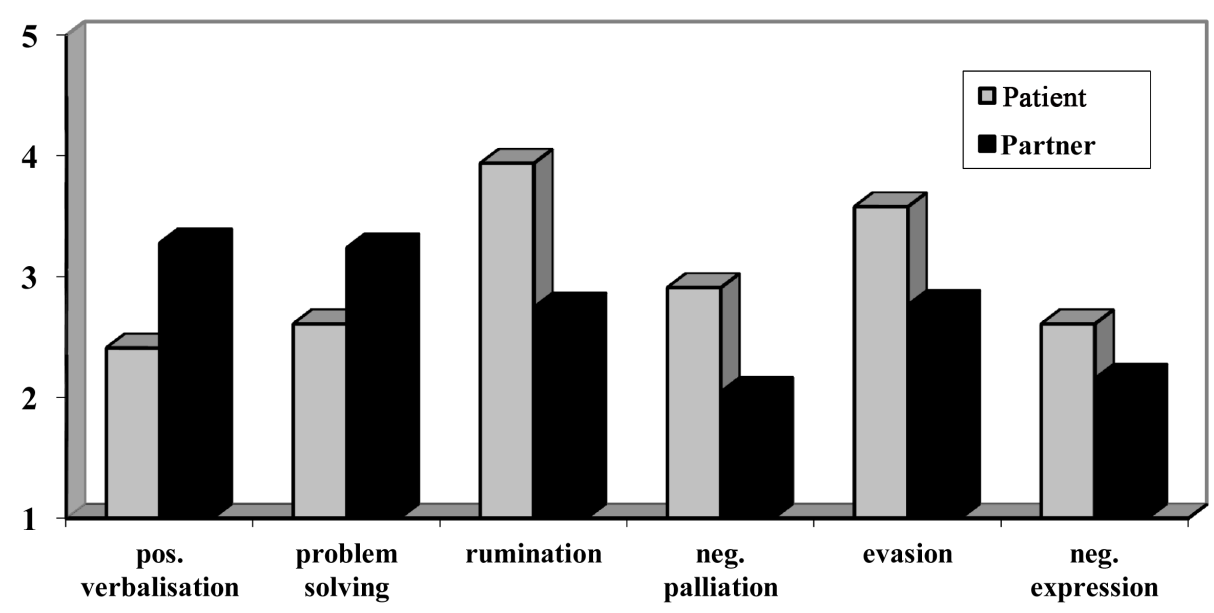

Figure 1. Significant differences and mean values of individual coping strategies. All subcategories show significant differences, Y-axe: 1 = never; 5 = mostly.

Table 2. Sample means and standard deviations for stress by group.

\begin{tabular}{cccccccccc}
\hline Variable & \multicolumn{2}{c}{$\mathrm{G} 1(\mathrm{n}=16)$} & \multicolumn{2}{c}{$\mathrm{G} 2(\mathrm{n}=21)$} & \multicolumn{2}{c}{$\mathrm{G} 3(\mathrm{n}=18)$} & \multicolumn{2}{c}{$\mathrm{G} 4(\mathrm{n}=7)$} \\
\cline { 2 - 9 } & $M$ & $S D$ & $M$ & $S D$ & $M$ & $S D$ & $M$ & \\
Wives & & & & & & & & \\
Marriage & 3.25 & 0.99 & 2.40 & 0.72 & 3.15 & 0.88 & 2.25 & 1.04 \\
Well-Being & 2.29 & 0.70 & 2.62 & 0.65 & 1.71 & 0.50 & 2.17 & 0.81 \\
Household & 2.62 & 0.75 & 2.58 & 0.81 & 1.84 & 0.65 & 2.33 & 1.19 \\
Outside & 2.39 & 0.91 & 2.61 & 1.03 & 1.64 & 0.80 & 2.39 & 0.65 \\
Husbands & & & & & & & & \\
Marriage & 2.54 & 0.66 & 1.70 & 0.62 & 3.20 & 0.67 & 2.12 & 0.61 \\
Well-Being & 1.50 & 0.40 & 1.51 & 0.29 & 2.45 & 0.72 & 2.30 & 0.25 \\
Household & 1.85 & 0.37 & 1.82 & 0.75 & 2.55 & 1.05 & 2.81 & 0.56 \\
Outside & 1.97 & 0.46 & 1.82 & 0.71 & 2.66 & 0.74 & 2.89 & 0.78 \\
\hline
\end{tabular}

${ }^{\mathrm{a}} \mathrm{G} 1$ = distressed couples with a depressed wife. G2 = nondistressed couples with a depressed wife. G3 = distressed couples with a depressed husband. $\mathrm{G} 4=$ nondistressed couples with a depressed husband.

Table 3. Sample means and standard deviations for individual coping by group.

\begin{tabular}{cccccccccc}
\hline Variable & \multicolumn{2}{c}{$\mathrm{G} 1(\mathrm{n}=16)$} & \multicolumn{2}{c}{$\mathrm{G} 2(\mathrm{n}=21)$} & \multicolumn{2}{c}{$\mathrm{G} 3(\mathrm{n}=18)$} & \multicolumn{2}{c}{$\mathrm{G} 4(\mathrm{n}=7)$} \\
\cline { 2 - 9 } Wives & $M$ & $S D$ & $M$ & $S D$ & $M$ & $S D$ & $M$ & $S D$ \\
Rumination & & & & & & & & \\
Positive Verbalisation & 4.21 & 0.47 & 3.98 & 0.72 & 2.96 & 0.62 & 2.90 & 0.50 \\
Problem Solution & 2.44 & 0.91 & 2.53 & 0.61 & 3.35 & 0.84 & 3.05 & 0.52 \\
Neg. Emotion Expression & 2.75 & 0.61 & 2.52 & 0.51 & 3.53 & 0.42 & 3.32 & 0.67 \\
Neg. Palliation & 3.15 & 0.61 & 2.38 & 0.75 & 2.53 & 0.78 & 2.57 & 0.69 \\
$\quad$ Evasion & 3.00 & 0.66 & 3.04 & 0.79 & 2.02 & 0.65 & 2.38 & 0.52 \\
$\quad$ Husbands & 3.00 & 1.32 & 3.71 & 0.96 & 2.56 & 1.04 & 2.57 & 1.27 \\
Rumination & & & & & & & & \\
Positive Verbalisation & 2.82 & 0.63 & 2.48 & 0.74 & 3.86 & 0.50 & 3.40 & 0.61 \\
Problem Solution & 3.35 & 0.74 & 3.24 & 1.04 & 2.33 & 0.89 & 2.14 & 0.38 \\
Neg. Emotion Expression & 3.17 & 0.55 & 3.02 & 0.83 & 2.60 & 0.63 & 2.61 & 0.78 \\
Neg. Palliation & 2.15 & 0.67 & 1.73 & 0.42 & 2.45 & 0.73 & 2.48 & 0.50 \\
$\quad$ Evasion & 2.10 & 0.70 & 1.93 & 0.64 & 2.81 & 0.74 & 2.52 & 0.94 \\
\end{tabular}

${ }^{\mathrm{a}} \mathrm{G} 1$ = distressed couples with a depressed wife. G2 = nondistressed couples with a depressed wife. G3 = distressed couples with a depressed husband. G4 = nondistressed couples with a depressed husband. 
There was also a significant multivariate effect (Hotteling's Trace) for subscales of individual coping attributable to gender $(F(1,58)=6.16, p \leq 0.001)$. Follow-up univariate ANOVAs indicated significantly greater rumination $(F(1,58)=8.35, p \leq 0.01)$ and negative emotional expression $(F(1,58)=14.91, p \leq 0.001)$ in women. Men showed a marginal tendency toward more evasion $(F(1,58)=5.59, p \leq 0.1)$ (see Table 4).

\subsection{Depression, Dyadic Coping and Gender}

Hypotheses: Existing results suggest there should be more emotion focused and less problem focused dyadic coping provided by depressed persons compared to their partners. For gender there should be more stress communication in women and possibly more negative dyadic coping in men.

Results: There were no significant multivariate effects for depression (Hotteling's Trace) $(F(1,58)=1.02, n s$.) or significant effects for follow-up analysis of subscales for self-reported dyadic coping. However, there was a significant multivariate effect (Hotteling's Trace) on self-reported dyadic coping attributable to gender $(F(1,58)$ $=6.16, p \leq 0.001)$. Univariate follow-up analyses indicated more problem focused $(F(1,58)=16.97, p \leq 0.001)$ and emotional stress communication $(F(1,58)=11.52, p \leq 0.01)$ and negative support $(F(1,58)=9.83, p \leq 0.01)$ in women than men (see Table 4, Table 5).

For observed dyadic coping, we found also no significant multivariate effects attributable to depression on either relative frequency $(\mathrm{rf})(F(1,58)=0.35, n s$. $)$ or relative duration $(\mathrm{rd})(F(1,58)=0.57, n s$. $)$ of observed dyadic coping behavior. Also, follow-up univariate ANOVAs using the subscales of dyadic coping behavior showed no significant index person effects. There were, however, significant multivariate gender effects for relative frequency $(F(1,58)=8.26, p \leq 0.001)$ and relative duration $(F(1,58)=2.72, p \leq 0.05)$ of dyadic coping behaviors. Additionally follow-up univariate ANOVAS (see Table 3) revealed a significant main effect of gender on relative duration $(F(1,58)=8.41, p \leq 0.05)$ and frequency $(F(1,58)=11.77, p \leq 0.05)$ of problem focused stress communication. Likewise, a significant effect was observed on relative duration of emotional focused stress communication $(F(1,58)=7.31, p \leq 0.05)$, with wives displaying higher levels than husbands. On the other hand, husbands showed higher values in relative duration $(F(1,58)=3.27, p \leq 0.05)$ and frequency $(F(1,58)=5.37, p \leq 0.05)$ of negative support as well as lower values in relative duration of verbal emotional support $(F(1,58)=5.37, p \leq 0.05)$ compared to wives (see Table 6 ).

Table 4. MANOVA and ANOVA for subscale for different coping questionnaires.

\begin{tabular}{|c|c|c|c|c|c|}
\hline \multirow{2}{*}{$\begin{array}{c}\text { Variable } \\
\text { Questionnaires }\end{array}$} & \multicolumn{2}{|c|}{ Group (3.58) } & \multicolumn{2}{|c|}{ Gender $(1,58)$} & \multirow{2}{*}{$\begin{array}{c}\text { group x gender (1.58) } \\
\mathrm{F}\end{array}$} \\
\hline & $\mathrm{F}$ & effects & $\mathrm{F}$ & effects & \\
\hline \multicolumn{6}{|l|}{ Individual Coping } \\
\hline positive verbalisation & 0.51 & & 0.22 & & $11.95^{*}$ \\
\hline problem solving & 1.73 & & 0.86 & & $10.03^{*}$ \\
\hline rumination & 2.10 & & $8.35^{*}$ & $\mathrm{w}>\mathrm{h}$ & $30.02^{*}$ \\
\hline negative palliation & 0.22 & & $3.61^{+}$ & & $13.76^{*}$ \\
\hline evasion & 0.63 & & $3.34^{+}$ & & $6.91^{*}$ \\
\hline negative expression & $4.81^{*}$ & $1>2$ & $14.91^{*}$ & $\mathrm{w}>\mathrm{h}$ & $14.91^{*}$ \\
\hline \multicolumn{6}{|l|}{ Dyadic coping } \\
\hline \multicolumn{6}{|l|}{ Stress Communication } \\
\hline problemfocused & $2.33^{+}$ & & $16.97^{*}$ & $\mathrm{w}>\mathrm{h}$ & 0.60 \\
\hline emotional & 1.90 & & $11.52^{*}$ & $\mathrm{w}>\mathrm{h}$ & 1.35 \\
\hline \multicolumn{6}{|l|}{ Support } \\
\hline problemfocused & $8.09^{* * * *}$ & $2>1 / 3$ & 0.00 & & 1.61 \\
\hline emotional & $17.07^{* * *}$ & $2>1 / 3$ & 1.54 & & 1.68 \\
\hline negative & $6.61^{* * *}$ & $1 / 3>2$ & $9.83^{* *}$ & $\mathrm{w}>\mathrm{h}$ & $2.42^{*}$ \\
\hline
\end{tabular}

${ }^{\mathrm{a}} \mathrm{G} 1$ = distressed couples with a depressed wife; G2= nondistressed couples with a depressed wife. G3= distressed couples with a depressed husband; $\mathrm{G} 4=$ nondistressed couples with a depressed husband. $\mathrm{w}=$ wife. $\mathrm{h}=$ husband. $\mathrm{d}=$ depressed. $\mathrm{p}=$ partner. ${ }^{*} p<0.05{ }^{+} p<.1$. 
Table 5. Means and standard deviations for self-reported dyadic coping by group.

\begin{tabular}{|c|c|c|c|c|c|c|c|c|}
\hline \multirow{2}{*}{ Questionnaire } & \multicolumn{2}{|c|}{$\mathrm{G} 1(\mathrm{n}=16)$} & \multicolumn{2}{|c|}{$\mathrm{G} 2(\mathrm{n}=21)$} & \multicolumn{2}{|c|}{ G3 $(n=18)$} & \multicolumn{2}{|c|}{$\mathrm{G} 4(\mathrm{n}=7)$} \\
\hline & $M$ & $S D$ & $M$ & $S D$ & $M$ & $S D$ & $M$ & $S D$ \\
\hline \multicolumn{9}{|l|}{ Wives } \\
\hline \multicolumn{9}{|c|}{ Stress Communication } \\
\hline Problem Focused & 3.37 & 1.50 & 3.62 & 1.26 & 3.09 & 1.23 & 4.43 & 1.10 \\
\hline Emotion Focused & 3.53 & 1.26 & 3.93 & 1.22 & 3.18 & 1.19 & 4.57 & 0.73 \\
\hline \multicolumn{9}{|l|}{ Support } \\
\hline Problem Focused & 2.83 & 0.96 & 4.18 & 0.98 & 3.48 & 0.93 & 4.29 & 0.51 \\
\hline Emotion Focused & 2.45 & 0.67 & 3.68 & 0.69 & 2.85 & 0.66 & 3.84 & 0.45 \\
\hline Negative & 2.50 & 1.13 & 1.46 & 0.59 & 2.36 & 0.98 & 1.68 & 0.43 \\
\hline \multicolumn{9}{|l|}{ Husbands } \\
\hline \multicolumn{9}{|l|}{ Stress Communication } \\
\hline Problem Focused & 2.78 & 0.73 & 2.71 & 0.86 & 2.47 & 1.02 & 3.00 & 0.87 \\
\hline Emotion Focused & 2.69 & 0.87 & 3.00 & 1.17 & 3.12 & 1.24 & 3.21 & 1.68 \\
\hline \multicolumn{9}{|l|}{ Support } \\
\hline Problem Focused & 3.29 & 0.89 & 4.14 & 0.95 & 3.28 & 0.85 & 4.10 & 0.76 \\
\hline Emotion Focused & 2.93 & 0.67 & 3.75 & 0.63 & 2.81 & 0.67 & 3.84 & 0.62 \\
\hline Negative & 1.71 & 0.74 & 1.30 & 0.28 & 1.99 & 0.67 & 1.64 & 0.45 \\
\hline
\end{tabular}

${ }^{\mathrm{a}} \mathrm{G} 1$ = distressed couples with a depressed wife. G2 = nondistressed couples with a depressed wife. G3 = distressed couples with a depressed husband. G4 = nondistressed couples with a depressed husband.

Table 6. MANOVA and ANOVA for behavior code of the dyadic coping.

\begin{tabular}{|c|c|c|c|c|c|c|c|c|c|c|}
\hline \multirow{3}{*}{ Behavior codes } & \multirow{2}{*}{\multicolumn{2}{|c|}{$\begin{array}{c}\mathrm{G} 1(\mathrm{n}=16) \\
\mathrm{F}\end{array}$}} & \multirow{2}{*}{\multicolumn{2}{|c|}{$\begin{array}{c}\text { G2 }(\mathrm{n}=21) \\
\text { Effects }\end{array}$}} & \multirow{2}{*}{\multicolumn{2}{|c|}{$\begin{array}{c}\mathrm{G} 3(\mathrm{n}=18) \\
\mathrm{F}\end{array}$}} & \multicolumn{2}{|c|}{$\mathrm{G} 4(\mathrm{n}=7)$} & \multirow{2}{*}{\multicolumn{2}{|c|}{$\mathrm{F}$}} \\
\hline & & & & & & & & & & \\
\hline & $r d$ & $r f$ & $r d$ & $r f$ & $r d$ & $r f$ & $r d$ & $r f$ & $r d$ & $r f$ \\
\hline \multicolumn{11}{|l|}{ Communication } \\
\hline problemfocused & $2.80^{*}$ & $2.73^{*}$ & $2>3$ & $2>3$ & $8.41^{*}$ & $11.77^{*}$ & $\mathrm{w}>\mathrm{h}$ & $\mathrm{w}>\mathrm{h}$ & 1.44 & 1.22 \\
\hline emotional & $2.33^{+}$ & $3.51^{*}$ & & $4>1 / 3$ & $7.31^{*}$ & 2.29 & $\mathrm{w}>\mathrm{h}$ & & 0.33 & 1.04 \\
\hline \multicolumn{11}{|l|}{ Coping } \\
\hline problemfocused & 0.31 & .928 & & & 0.78 & 2.44 & & & 1.70 & $3.01^{*}$ \\
\hline nonverbal emotional & $5.77^{*}$ & $4.72^{*}$ & $4>1 / 3$ & $4>1 / 3$ & 0.17 & 0.22 & & & 2.00 & 1.75 \\
\hline emotional verbal & 0.86 & $3.36^{*}$ & & $4>1 / 3$ & 1.76 & $4.06^{*}$ & & $\mathrm{w}>\mathrm{h}$ & 0.17 & 0.73 \\
\hline negative & 1.35 & 1.43 & & & $3.27^{*}$ & $5.37^{*}$ & $\mathrm{~h}>\mathrm{w}$ & $\mathrm{h}>\mathrm{w}$ & 0.25 & 0.18 \\
\hline
\end{tabular}

${ }^{\mathrm{a}} \mathrm{G} 1$ = distressed couples with a depressed wife; $\mathrm{G} 2=$ nondistressed couples with a depressed wife. $\mathrm{G} 3=$ distressed couples with a depressed husband; $\mathrm{G} 4$ = nondistressed couples with a depressed husband. $\mathrm{w}=$ wife; $\mathrm{h}=$ husband. $\mathrm{d}=$ depressed. $\mathrm{p}=$ partner. $\mathrm{rd}=$ relative duration. $\mathrm{rf}=$ relative frequency. ${ }^{*} p<0.05 ;{ }^{+} p<0.1$.

\subsection{Depression, Couple Distress, Dyadic Coping and Gender}

Hypotheses: Prior research suggests that distressed couples with a depressed partner compared to non-depressed 
couples with a depressed partner should have more couple related stress, higher negative and lower positive dyadic coping.

Results: There was a significant multivariate group effect (Hotteling's Trace) $(F(3,58)=3.72, p \leq 0.001)$ for stress across life domains. Follow-up ANOVAs with subscales of stress indicated a significant group difference only for stress associated with the marital relationship. This was accounted for by the significantly greater stress reported by G1 and G3 (i.e. the maritally distressed groups) compared to G2 and G4 (the maritally non-distressed groups) $(F(3,58)=9,18, p \leq 0.001)$.

For self-reported dyadic coping, there was a significant multivariate group effect on self-reported dyadic coping (Hotteling's Trace) $(F(3,58)=1.30, p \leq 0.01)$. On specific subscales (see Table 4), significant group effects were found for lower negative $(F(3,58)=6.69, p \leq 0.01)$, higher emotional $(F(3,58)=17.07, p \leq 0.001)$ and greater problem-focused support $(F(3,58)=8.09, p \leq 0.01)$ in $\mathrm{G} 2$ (nondistressed, depressed wife) compared to G1 (distressed, depressed wife) and G3 (distressed, depressed husband).

Examining observed dyadic coping, significant multivariate group effects (Hotteling's Trace) for relative duration $(\mathrm{rd})(F(3,58)=2.04, p \leq 0.05)$ and relative frequency $(\mathrm{rf})(F(3,58)=1.77, p \leq 0.05)$ of dyadic coping categories were found. Follow-up analyses examining specific subscales of observed dyadic coping (see Table 6) indicated that nondistressed couples with a depressed wife (G2) demonstrated significantly higher values in relative duration $(F(3,58)=2.80, p \leq 0.05)$ and frequency $(F(3,58)=2.73, p \leq 0.05)$ of problem focused stress communication, although this comparison was only significant in comparison to distressed couples with a depressed husband (G3). Conversely, nondistressed couples with a depressed husband (G4) showed a significantly higher relative frequency $(F(3,58)=3.51, p \leq 0.05)$ of emotionally focused stress communication, although this was only significant in comparison to distressed couples with a depressed wife (G1) or with a depressed husband (G3). Further nondistressed couples with a depressed husband (G4) also had greater relative duration $(F(3,58)=$ $5.77, p \leq 0.05)$ and frequency $(F(3,58)=4.72, p \leq 0.05)$ of nonverbal emotional support as well as a greater relative frequency $(F(3,58)=3.36, p \leq 0.05)$ of verbal emotional support compared to distressed couples with depressed partners (G1, G3).

In contrast, there was no significant multivariate effect (Hotteling's Trace) for group related to use of individual coping $(F(3,58)=2.25, p \leq 0.01)$.

\section{Discussion}

We investigated group, gender and index person effects on stress and coping responses by comparing groups of maritally distressed and non-distressed couples in which either the male or female partner was suffering from depression. The goal of the study was to investigate the potential use of coping oriented couple approaches (e.g. COCT) and to specify potential impacts of gender differences in stress and coping in areas that might influence the implementation of such interventions for depression. Because of our use of both self-report and observational measures we are able to help reconcile some previous inconsistencies in the literature. The most interesting and innovative findings were: 1) there are different stress and coping patterns in couples with a depressed partner depending on gender and 2) especially in couples with depressed wives, dyadic coping figures as an important resource against the negative interplay between depression and marital distress.

\subsection{Depression, Stress Generation and Gender}

Replicating previous reports (Beach et al., 2014) we found greater perceived stress in several life areas (marriage, well-being, household, outside world) and deficits in self-reported individual coping strategies in depressed men and women compared to their non-depressed partners (Ptacek et al., 1994). Gender differences in these domains were observed, but were modest in comparison to those observed for depression. We identified greater general stress levels, greater vulnerability to distress in the marital relationship and lower well-being for women compared to men (see also Almeida \& Kessler, 1998) as well as greater use of rumination and negative emotional expression concerning individual coping for women compared to men (Tamres et al., 2002).

\subsection{Depression, Dyadic Coping and Gender}

There were no significant group differences for perceived or observed dyadic coping, and no significant effects 
attributable to depression. However, there were significant gender differences. We found greater self-reported and observed problem and emotional focused stress communication for women, replicating previous findings (Bodenmann et al., 2006). Some interesting discrepancies were noted comparing the gender differences that emerged for self-reported behavior and observed behavior for negative support. For self-reported behavior, women reported engaging in more negative support than their partners. However, observed behavior during the dyadic coping task indicated more negative coping and less emotional support by men compared to women. These results suggest that some self-reported gender differences may be the result of wives more negative cognitive strategies and self-statements, rather than actual behavior, underscoring the need for direct observation to examine marital interaction in the context of depression (Almeida \& Kessler, 1998; Beach et al., 2014).

In broad brush, the current results seem compatible with a gender-sensitive version of a model presented by Coyne (e.g. Benzano \& Coyne, 2000). According to this elaborated model, gender typical stress and coping strategies become more accentuated in the context of depression. Increases of gender typical negative emotional self-verbalizations and negative statements in depressed women co-occur with withdrawal, ambivalence and negativity in male partners. Increases of gender typical withdrawal, ambivalence and negativity in support behavior in depressed men on the other hand is associated with more negative self-statements in female partner. We found a similar exaggeration of gender typical patterns in observed behavior in a conflict situation (Gabriel et al., 2010). Exaggeration of gender typical patterns in couples with a depressed partner could also explain the lack of significant differences between depressed persons and their partners to the extent that different behaviors are amplified for dyads with a male vs. female depressed spouse.

\subsection{Depression, Couple Distress, Dyadic Coping and Gender Differences}

Significant group differences were found indicating lower stress associated with the marital relationship and more functional self-reported and observed dyadic coping among those in maritally non-distressed couples compared to those in maritally distressed dyads. Examining group differences, we found the greatest nonverbal positivity and frequency of emotional stress regulation in the observed behavior of nondistressed couples with a depressed husband (G4), as well as greater positive and less negative self-perceived dyadic coping in nondistressed couples with a depressed wife (G2) compared to distressed couples with either female (G1) or male depressed partners (G3). Additionally, maritally satisfied couples with a depressed wife engaged in the most problem focused stress communication. These findings suggest a relative advantage of maritally satisfied couples with regard to use of dyadic coping strategies to compensate for gender typical deficits in depressed partners. However, this finding requires replication due to the relatively small size of this sample.

\subsection{Limitation of the Study}

Some caveats are in order. For example, it may be important to consider the potential impact of demographic differences between groups. There were more children in the two maritally distressed groups (G1, G3) and a more traditional division of household labor. Accordingly, this may have contributed to some of the observed group differences in stress and gender asymmetry, reinforcing the association of depression and marital distress. In addition, the power to detect significant differences for small to medium effect sizes was limited because of the relatively small cell sizes, particularly for satisfied couples with a depressed husband. Because the current sample was underpowered with regard to between group effects, it will be important to replicate observed group differences in future research. In addition, we did not use a control group without depressed individuals to investigate dyadic coping attributable to depression, and the couples in the current study typically had a depressed partner who was suffering from chronic depression (average 10 years), so results for dyadic coping might be different if first onset or recent depressive episodes were the focus of attention. In addition, the requirement that couples participating in the current study sample have a partner agreeing to participate on the study and to do either individual or couple treatment may limit the generalization of the present results to a general population of depressed persons.

\subsection{Future Prospects}

A key finding of the current investigation was that depressed persons reported greater stress and behaved in ways likely to generate future stress in their relationships, supporting a likely stress generation effect for depressed 
individuals in close relationships (cf. Beach et al., 2014; Hamman, 2006). In addition, we found exaggeration of gender typical reactions among depressed individuals compared to their partners and also exaggeration of gender differences in the context of marital distress, suggesting that exaggerated gender differences in stress- communication and coping may be a useful focus of attention in undercutting stress-generation and marital discord among couples with a depressed partner.

The inclusion of both partners allowed us to examine index patient effects as well as gender differences, drawing greater attention to the importance of including depressed persons and significant others in future research and therapy for depression. The current results support the potential use of coping oriented couple interventions to improve deficits and stress generation in depressed individuals in stable relationships. Especially for depressed women this coping oriented couple approaches has the potential to be particularly useful in supporting emotion regulation and preventing exaggerations of gender typical negativity and relationship stress. It is not surprising that dyadic coping varies with relationship well-being independent of depression or gender of the depressed person. But the current results on gender differences help better identify the nature of differences in dyadic stress coping strategies across different couple types, and the way these may influence well-being and relationship outcome. The current findings indicate the value of continued attention to adapting couple based treatments in response to specific gender and depression characteristics that may be most likely for different types of couples.

\section{Compliance with Ethical Standards}

Conflict of interest: Author A declares he/she has no conflict of interest. Author B declares he/she has no conflict of interest. Author C declares he/she has no conflict of interest.

Ethical approval: This article does not contain any studies with animals performed by any of the authors.

Ethical approval: All procedures performed in the study involving human participants were in accordance with the ethical standards of the institutional and national research committee and with the 1964 Helsinki declaration and its later amendments or comparable ethical standards.

Informed consent: Informed consent was obtained from all individual participants included in the study.

\section{Fund}

This study was supported by the Swiss National Science Foundation SNF 610-062901 and 100013-109547/1.

\section{References}

Almeida, D. M., \& Kessler, R. C. (1998). Everyday Stressors and Gender Differences in Daily Distress. Journal of Personality and Social Psychology, 75, 670-680. http://dx.doi.org/10.1037/0022-3514.75.3.670

American Psychiatric Association (1994). Diagnostic and Statistical Manual of Mental Disorders (4th ed.). Washington, DC: American Psychiatric Association.

Bakeman, R., \& Gottman, J. M. (1997). Observing Interaction: An Introduction to Sequential Analysis (2nd ed.). New York: Cambridge University Press. http://dx.doi.org/10.1017/cbo9780511527685

Beach, S. R. H., Whisman, M. A., \& Bodenmann, G. (2014). Couple, Parenting, and Interpersonal Therapies for Depression in Adults: Toward Common Clinical Guidelines within a Stress Generation Framework. In I. A. Gotlib, \& C. Hammen (Eds.), Handbook of Depression (3rd ed.: pp. 552-570). New York: Guilford Press.

Beach, S. R. H., Katz, J., Kim, S., \& Brody, G. H. (2003). Prospective Effects of Marital Satisfaction on Depressive Symptoms in Established Marriages: A Dyadic Model. Journal of Social and Personal Relationships, 20, 355-371. http://dx.doi.org/10.1177/0265407503020003005

Beach, S. R. H., Smith, D. A., \& Fincham, F. D. (1994). Marital Interventions for Depression: Empirical Foundation and Future Prospects. Applied and Preventive Psychology, 3, 233-250. http://dx.doi.org/10.1016/S0962-1849(05)80097-6

Beach, S. R. H., \& O’Leary, K. D. (1993). Dysphoria and Marital Discord: Are Dysphoric Individuals at Risk for Marital Maladjustment? Journal of Marital and Family Therapy, 19, 355-368. http://dx.doi.org/10.1111/j.1752-0606.1993.tb00998.x

Beck, A. T., \& Steer, R. A. (1987). Beck Depression Inventory-Manual. San Antonio, TX: The Psychological Corporation.

Benazon, N. R., \& Coyne, J. C. (2000). Living with a Depressed Spouse. Journal of Family Psychology, 14, 71-79.

http://dx.doi.org/10.1037/0893-3200.14.1.71 
Bodenmann, G., Meuwly, N., Bradbury, T., Gmelch, S., \& Ledermann, T. (2010). Stress, Anger and Verbal Aggression in Intimate Relationships: Moderating Effects of Trait Anger and Dyadic Coping. Journal of Social and Personal Relationships, 27, 408-424. http://dx.doi.org/10.1177/0265407510361616

Bodenmann, G. (2008). Dyadisches Coping Inventar [Dyadic Coping Inventory]. Manual. Bern: Huber.

Bodenmann, G., Plancherel, B., Beach, S. R. H., Widmer, K., Gabriel, B., Charvoz, L., Meuwly, N., Hautzinger, M., \& Schramm, E. (2008). Effects of Coping-Oriented Couples Therapy on Depression: A Randomized Clinical Trial. Journal of Consulting and Clinical Psychology, 76, 944-954. http://dx.doi.org/10.1037/a0013467

Bodenmann, G., Pihet, S., \& Kayser, K. (2006). The Relationship between Dyadic Coping and Marital Quality: A 2-Year Longitudinal Study. Journal of Family Psychology, 20, 485-493. http://dx.doi.org/10.1037/0893-3200.20.3.485

Bodenmann, G., Charvoz, L., Widmer, K., \& Bradbury, T. N. (2004). Differences in Individual and Dyadic Coping among Low and High Depressed, Partially Remitted, and Nondepressed Persons. Journal of Psychopathology and Behavioral Assessment, 26, 75-85. http://dx.doi.org/10.1023/B:JOBA.0000013655.45146.47

Bodenmann, G. (2000). Stress und Coping bei Paaren [Stress and Coping in Couples]. Göttingen: Hogrefe.

Bodenmann, G. (1997). Kodiersystem zur Erfassung des emotionalen supportiven dyadischen Copings (SEDC). Erweiterte und adaptierte Version. Unveröffentlichtes Manual. Fribourg: Universität Fribourg.

Bortz, J. (1993). Statistik [Statistic]. Berlin: Springer. http://dx.doi.org/10.1007/978-3-662-10034-9

Bourquard, E., Bodenmann, G., \& Perrez, M. (1992-2005). CAOS. Computer Aided Observation System. Fribourg: Universität Fribourg.

Carver, C. S., Scheier, M. F., \& Weintraub, J. K. (1989). Assessing Coping Strategies: A Theoretically Based Approach. Journal of Personality and Social Psychology, 56, 267-283. http://dx.doi.org/10.1037/0022-3514.56.2.267

Christensen, A., \& Shenk, J. L. (1991). Communication, Conflict, and Psychological Distance in Nondistressed, Clinic, and Divorcing Couples. Journal of Consulting and Clinical Psychology, 59, 458-463.

http://dx.doi.org/10.1037/0022-006X.59.3.458

Christensen, A., \& Heavey, C. L. (1990). Gender and Social Structure in the Demand/Withdraw Pattern of Marital Conflict. Journal of Personality and Social Psychology, 59, 73-81. http://dx.doi.org/10.1037/0022-3514.59.1.73

Cohen, J. (1960). A Coefficient of Agreement for Nominal Scales. Educational and Psychological Measurement, 20 , 37-46. http://dx.doi.org/10.1177/001316446002000104

Cohen, J. (1988). Statistical Power Analysis for the Behavioral Sciences (2nd ed.). New York: Erlbaum.

Coyne, J. C., Thompson, R., \& Palmer, S. C. (2002). Marital Quality, Coping with Conflict, Marital Complaints, and Affection in Couples with a Depressed Wife. Journal of Family Psychology, 16, $26-37$.

http://dx.doi.org/10.1037/0893-3200.16.1.26

Cranford, J. A. (2004). Stress-Buffering or Stress-Exacerbation? Social Support and Social Undermining as Moderators of the Relationship between Perceived Stress and Depressive Symptoms among Married People. Personal Relationships, 11, 23-40. http://dx.doi.org/10.1111/j.1475-6811.2004.00069.x

Davila, J., Karney, B. R., Hall, T. W., \& Bradbury, T. N. (2003). Depressive Symptoms and Marital Satisfaction: Within-Subject Associations and the Moderating Effects of Gender and Neuroticism. Journal of Family Psychology, 17, 557570. http://dx.doi.org/10.1037/0893-3200.17.4.557

Eldridge, K. A., \& Christensen, A. (2002). Demand-Withdraw Communication during Couple Conflict: A Review and Analysis. In P. Noller, \& J. A. Feeney (Eds.), Understanding Marriage: Developments in the Study of Couple Interaction (pp. 289-322). New York: Cambridge University Press. http://dx.doi.org/10.1017/CBO9780511500077.016

Falconier, M. K., Nussbeck, F., \& Bodenmann, G. (2013). Immigration Stress and Relationship Satisfaction in Latino Couples: The Role of Dyadic Coping. Journal of Social and Clinical Psychology, 32, 813-843. http://dx.doi.org/10.1521/jscp.2013.32.8.813

Felsten, G. (2002). Minor Stressors and Depressed Mood: Reactivity Is More Strongly Correlated than Total Stress. Stress and Health: Journal of the International Society for the Investigation of Stress, 18, 75-81.

http://dx.doi.org/10.1002/smi.925

Gabriel, B., Beach, S. R. H., \& Bodenmann, G. (2010). Depression, Marital Satisfaction and Communication in Couples: Investigating Gender Differences. Behavior Therapy, 41, 306-316. http://dx.doi.org/10.1016/j.beth.2009.09.001

Gottman, J. M. (1994). What Predicts Divorce? Hillsdale, NJ: Erlbaum.

Hahlweg, K. (1996). Fragebogen zur Partnerschaftdiagnostik (PFB) [Partnership questionnaire]. Göttingen: Hogrefe.

Hammen, C. (2006). Stress Generation in Depression: Reflections on Origins, Research, and Future Directions. Journal of Clinical Psychology, 62, 1065-1082. http://dx.doi.org/10.1002/jclp.20293

Hautzinger, M., Bailer, M., Worall, H., \& Keller, F. (1996). Beck-Depression-Inventar (BDI). Testhandbuch [Beck Depression Inventory (BDI). Manual]. Bern: Huber. 
Johnson, S. L., \& Jacob, T. (2000). Sequential Interactions in the Marital Communication of Depressed Men and Women. Journal of Consulting and Clinical Psychology, 68, 4-12. http://dx.doi.org/10.1037/0022-006X.68.1.4

Johnson, S. L., \& Jacob, T. (1997). Marital Interactions of Depressed Men and Women. Journal of Consulting and Clinical Psychology, 65, 15-23. http://dx.doi.org/10.1037/0022-006X.65.1.15

Kanner, A. D., Coyne, J. C., Schaefer, C., \& Lazarus, R. S. (1981). Comparison of Two Modes of Stress Measurements: Daily Hassles and Uplifts versus Major Life Events. Journal of Behavioral Medicine, 4, 1-39. http://dx.doi.org/10.1007/BF00844845

Kenny, D. A., Kashy, D. A., \& Cook, W. L. (2006). Dyadic Data Analysis. New York: Guilford.

Ko, L., \& Lewis, M. (2011). The Role of Giving and Receiving Emotional Support in Depressive Symptomatology in Older Couples: An Application of the Actor-Partner Interdependence Model. Journal of Personality and Social Psychology, 28, 83-99. http://dx.doi.org/10.1177/0265407510387888

McCall, M. E., \& Struthers, N. J. (1994). Sex, Sex-Role Orientation and Self-Esteem as Predictors of Coping Style. Journal of Social Behavior \& Personality, 9, 801-810.

Monroe, S. M., \& Simons, A. D. (1991). Diathesis-Stress Theories in the Context of Life Stress Research: Implications for the Depressive Disorders. Psychological Bulletin, 110, 406-425. http://dx.doi.org/10.1037/0033-2909.110.3.406

Moos, R. H., Schutte, K. K., Brennan, P. L., \& Moos, B. S. (2005). The Interplay between Life Stressors and Depressive Symptoms among Older Adults. The Journals of Gerontology: Series B: Psychological Sciences and Social Sciences, 60B, 199-206. http://dx.doi.org/10.1093/geronb/60.4.P199

Neff, L. A., \& Karney, B. R. (2005). Gender Differences in Social Support: A Question of Skill or Responsiveness? Journal of Personality and Social Psychology, 88, 79-90. http://dx.doi.org/10.1037/0022-3514.88.1.79

Papageorgiou, C., \& Wells, A. (2003). An Empirical Test of a Clinical Metacognitive Model of Rumination and Depression. Cognitive Therapy and Research, 27, 261-273. http://dx.doi.org/10.1023/A:1023962332399

Pasch, L. A., \& Bradbury, T. N. (1998). Social Support, Conflict, and the Development of Marital Dysfunction. Journal of Consulting and Clinical Psychology, 66, 219-230. http://dx.doi.org/10.1037/0022-006X.66.2.219

Ptacek, J. T., Smith, R. E., \& Dodge, K. L. (1994). Gender Differences in Coping with Stress: When Stressor and Appraisals Do Not Differ. Personality and Social Psychology Bulletin, 20, 421-430. http://dx.doi.org/10.1177/0146167294204009

Rehman, U. S., Gollan, J., \& Mortimer, A. R. (2008). The Marital Context of Depression: Research, Limitations, and New Directions. Clinical Psychology Review, 28, 179-198. http://dx.doi.org/10.1016/j.cpr.2007.04.007

Rohde, P., Lewinsohn, P. M., Tilson, M., \& Seeley, J. R. (1990). Dimensionality of Coping and Its Relation to Depression. Journal of Personality and Social Psychology, 58, 499-511. http://dx.doi.org/10.1037/0022-3514.58.3.499

Tamres, L. A., Janicki, D., \& Helgeson, W. S. (2002). Sex Differences in Coping Behavior: A Meta-Analytic Review and an Examination of Relative Coping. Personality and Social Psychology Review, 6, 2-30. http://dx.doi.org/10.1207/S15327957PSPR0601_1

Verhofstadt, L. L., Buysse, A., \& Ickes, W. (2007). Social Support in Couples: An Examination of Gender Differences Using Self-Report and Observational Methods. Sex Roles, 57, 267-282. http://dx.doi.org/10.1007/s11199-007-9257-6

Vingerhoets, A. J., \& Van Heck, G. L. (1990). Gender, Coping and Psychosomatic Symptoms. Psychological Medicine, 20, 125-135. http://dx.doi.org/10.1017/S0033291700013301

Whisman, M. A. (2001). Depression and Marital Distress: Findings from Clinical and Community Studies. In S. R. H. Beach (Ed.), Marital and Family Process in Depression (pp. 3-24). Washington DC: American Psychological Association.

Wittchen, H. U., Zaudig, M., Schramm, E., Spengler, P., Mombour, W., Klug, J., \& Horn, R. (1990). Strukturiertes Klinisches Interview für DSM-III-R (SKID) [Structured Clinical Interview (SCID)]. Weinheim: Beltz Test Gesellschaft. 


\section{Submit or recommend next manuscript to SCIRP and we will provide best service for you:}

Accepting pre-submission inquiries through Email, Facebook, Linkedin, Twitter, etc A wide selection of journals (inclusive of 9 subjects, more than 200 journals)

Providing a 24-hour high-quality service

User-friendly online submission system

Fair and swift peer-review system

Efficient typesetting and proofreading procedure

Display of the result of downloads and visits, as well as the number of cited articles

Maximum dissemination of your research work

Submit your manuscript at: http://papersubmission.scirp.org/ 